\title{
The European Heart Failure Self-care Behaviour Scale: New insights into factorial structure, reliability, precision and scoring procedure
}

\author{
Ercole Vellone, Tiny Jaarsma, Anna Strömberg, Roberta Fida, Kristofer Franzén Årestedt, \\ Gennaro Rocco, Antonello Cocchieri and Rosaria Alvaro
}

\section{Linköping University Post Print}

\section{Tweet}

N.B.: When citing this work, cite the original article.

Original Publication:

Ercole Vellone, Tiny Jaarsma, Anna Strömberg, Roberta Fida, Kristofer Franzén Årestedt, Gennaro Rocco, Antonello Cocchieri and Rosaria Alvaro, The European Heart Failure Selfcare Behaviour Scale: New insights into factorial structure, reliability, precision and scoring procedure, 2014, Patient Education and Counseling, (94), 1, 97-102.

http://dx.doi.org/10.1016/j.pec.2013.09.014

Copyright: Elsevier

http://www.elsevier.com/

Postprint available at: Linköping University Electronic Press http://urn.kb.se/resolve?urn=urn:nbn:se:liu:diva-104293 
The European Heart Failure Self-care Behaviour Scale: New insights into factorial structure, reliability, precision and scoring procedure

Ercole Vellone

Department of Biomedicine and Prevention

Tor Vergata University, Rome, Italy

Tiny Jaarsma

Department of Social and Welfare Studies, Faculty of Health Sciences,

University of Linköping, Norrköping, Sweden

Anna Stromberg

Department of Medical and Health Sciences, Faculty of Health Sciences

University of Linköping, Sweden

Roberta Fida

Department of Psychology, Sapienza University, Rome, Italy

Kristofer Årestedt

Faculty of Health and Life Sciences, Linneaeus University,

Kalmar, Sweden; Department of Medicine and Health Sciences,

Linköping University, Linköping, Sweden.

Gennaro Rocco

Center of Excellence for Nursing Scholarship, Rome, Italy

Antonello Cocchieri

Department of Biomedicine and Prevention

Tor Vergata University, Rome, Italy

Rosaria Alvaro

Department of Biomedicine and Prevention

Tor Vergata University, Rome, Italy

Corresponding author

Ercole Vellone

Department of Biomedicine and Prevention

Faculty of Medicine

Tor Vergata University

Via Montpellier, 1

00133, Rome, Italy

e-mail: ercole.vellone@uniroma2.it

Phone +39338 7491811; Fax + 390672596961 


\section{Abstract}

Objective. To evaluate a new factorial structure of the European Heart Failure Self-care Behaviour Scale 9-item version (EHFScBS-9), and to test its reliability, floor and ceiling effect, and precision. To propose a new 0-100 score with a higher score meaning better self-care.

Methods. A sample of 1,192 Heart Failure (HF) patients (mean age 72 years, 58\% male) was enrolled. Psychometric properties of the EHFScBS-9 were tested with confirmative factor analysis, factor score determinacy, determining the floor and ceiling effect, and evaluating the precision with the standard error of measurement (SEM) and the smallest real difference (SRD).

Results. We identified three well-fitting factors: consulting behaviour, autonomy-based adherence, and provider-based adherence (comparative fit index $=0.96$ ). Reliability ranged between 0.77 to 0.95. The EHFScBS-9 showed no floor and ceiling effect except for the provider-based adherence which had an expected ceiling effect. The SEM and the SRD indicated good precision of the EHFScBS-9.

Conclusion. The new factorial structure of the EHFScBS-9 showed supportive psychometric properties.

Practice implications. The EHFScBS-9 can be used to compute a total and specific scores for each identified factor. This may allow more detailed assessment and tailored interventions to improve self-care. The new score makes interpretation of the EHFScBS-9 easier.

\section{KEY WORDS}

Heart Failure, Self-care, Psychometrics, Instrument validity and reliability. 


\section{Introduction}

It is estimated that 15 million people are affected by HF in Europe [1], and this figure is enlarging due to the improved treatment of acute coronary events and aging of the population. HF is associated with frequent hospital admissions, emergency department visits, and low quality of life but better self-care has been shown to improve patients outcomes $[2,3]$.

To evaluate HF self-care and interventions to improve self-care reliable and valid instruments are needed. To date, only two tools are available in the literature: the European Heart Failure Self-care Behaviour Scale (EHFScBS) [4] and the Self-Care of Heart Failure Index v.6.2 (SCHFI v.6.2) [5, 6] which has also a caregiver version [7]. The EHFScBS was developed in 2003 [4] and was reduced to a 9-item scale (EHFScBS-9) in 2009. It consists of two factors: consulting behaviours and adherence to regimen [8].

\section{Examining the factorial structure of an instrument is very important to test its internal} validity. In fact, EFA and CFA determine if the theoretical dimensionality of a tool is supported and whether items designed to measure each dimension do so as expected [11].

So far, the factorial structure and the reliability of the EHFScBS-9 have shown less than optimal psychometric properties. In the 2009 study [8] Confirmatory Factor Analysis (CFA) showed poor normed fit index (NFI) and comparative fit indices (CFI) (0.76 and 0.77, respectively). Reliability testing demonstrated an adequate Cronbach's alpha for the total scale and the consulting behaviours factor (both $>0.80$ ), yet with a Cronbach's alpha of 0.56 for the adherence to regimen factor. The EHFScBS-9 was also tested in Germany and United States [9, 10]. In both studies construct validity was not supportive for all fit indices and reliability was adequate for the total scale and the consulting behaviours factor but not for the other extracted factors. 
A recent study [12] testing the psychometric properties of the SCHFI v.6.2, that is very similar in content to the EHFScBS-9, has shown that the items pertaining the adherence to treatment loaded on an "autonomous" and a "provider-directed" factor. This new factorial structure of the SCHFI v.6.2 has shown more supportive fit indices than prior analyses and has provided with a new insight in the dimensions of HF self-care.

The reliability of the EHFScBS-9 for the total scale and the consulting behaviours factor is supportive but it is not for the adherence with the regimen factor. However, psychometric literature has demonstrated that Cronbach's alpha is not a consistent estimator of scale reliability $[14,15]$. An alternative option to test reliability is the factor score determinacy coefficient [16], successfully used also on the SCHFI v.6.2 [12], which has never been used on the EHFScBS-9. In addition, the floor and ceiling effect as well as the responsiveness to change of the EHFScBS-9 have never been determined. These three characteristics can give insight into the precision of the scale. The EHFScBS-9 currently has a score from 9 to 45 with a higher score indicating worse self-care. A standardised score from 0 to 100 with a higher score indicating better self-care can make interpretation of the score easier. Therefore, the aims of this study were to: 1) evaluate a new factorial structure of the of the EHFScBS-9 based on the factorial structure of the SCHFI v.6.2;2) evaluate the reliability of the EHFScBS-9 by factor score determinacy coefficient; 3 ) evaluate the floor and ceiling effect of the EHFScBS-9 and its responsiveness to change; and 4) propose a 0 - 100 standardised score of the EHFScBS-9, where a higher score means better self-care.

\section{Methods}

\subsection{Design}

A cross-sectional design was used. 


\subsection{Sample and setting}

A sample of 1,192 patients with HF was enrolled in this study. Patients were recruited from cardiovascular outpatient clinics located in 28 provinces located in the North, Centre, and South of Italy. To be eligible in the study patients had to speak and understand the Italian language, had to have a confirmed diagnosis of $\mathrm{HF}$, and had not had an acute coronary event in the previous 3 months.

\subsection{Instruments}

The EHFScBS-9 was employed [8]. Each item uses a 5-point Likert scale from 1 ("completely agree") to 5 (“completely disagree”). The nine items can be grouped in two dimensions: consulting behaviours and adherence with the regimen. The consulting behaviours dimension investigates how often people with HF call their doctor/nurse in case of shortness of breath, ankle swelling, weight gain, and fatigue, whereas the adherence with the regimen dimension groups items that investigate how often patients weigh themselves, try to drink less water, follow a low-sodium diet, regularly take their medications, and exercise. The possible score is $9-45$, with a lower score indicating better self-care. For reasons of interpretation we introduced a standardised score from $0-100$ for the EHFScBS-9. The score was also reversed such that a higher score means better self-care. The translation and back-translation of the EHFScBS-9 into Italian language was performed in a prior study [8].

We also employed a sociodemographic and clinical questionnaire designed by the research team to collect sociodemographic (age, gender, marital status, and education) and clinical variables [New York Heart Association (NYHA) class, ejection fraction, and illness duration].

\subsection{Procedure}


This study was approved by the Institutional Review Boards of each centre where patients were recruited. Patients were approached during ambulatory visits, and nurses trained on the research protocol administered the instruments after informed consent was obtained.

\subsection{Statistical Analysis}

Sociodemographic and clinical variables were analysed with descriptive statistics (frequencies, means, standard deviations, medians, and interquartile ranges). Each of the nine items of the EHFScBS-9 underwent item analysis with computation of the median and interquartile range. CFA was performed to establish the construct validity of the scale considering the following fit indices:

Chi square, RMSEA, CFI, NNFI, and standardised root mean square residual (SRMR) [17]. According to $\mathrm{Hu}$ and Bentler [18] a model has a good fit if the RMSEA is up to 0.06 and in the lower bound of the $90 \%$ confidence interval, the CFI and NNFI are $\geq 95$, and the SRMRs are below 0.08. CFA was initially used to test the one-factor model of the EHFScBS-9, but because this analysis resulted in an inadequate fit $[$ Chi square $(27,1192)=551.17 ; \mathrm{p}<0.000 ; \mathrm{CFI}=0.86$; NNFI $=0.81 ;$ RMSEA $=0.13(90 \%$ CI $0.12-0.14)$; and SRMR $=0.08)]$, CFA was performed taking into consideration the factorial structure of the SCHFI v.6.2 that showed recently excellent fit indices [12]. As described above, the SCHFI v.6.2 [5] is a 22-item instrument that measures self-care of HF with three scales: self-care maintenance, self-care management, and self-care confidence. The first two of these scales are very similar in their content to the EHFScBS-9, and within each, a recent study [12] identified factors pertaining to "autonomous" self-care maintenance and management and factors pertaining to "provider-directed" self-care maintenance and management. The SCHFI v.6.2 item asking about salt restriction (corresponding to item number 7 of the EHFScBS-9) had a loading on the "provider-directed" self-care maintenance. The items of the EHFScBS-9 were similarly aggregated taking into consideration the factorial structure of the SCHFI v.6.2. Specifically, item numbers 1,5 , and 9 were hypothesised to be in a factor that we called "autonomous-based adherence" item numbers 2, 3, 4, and 6 were hypothesised to be in the factor 
“consulting behaviours" (already identified in prior studies [4, 8], and item numbers 7 and 8 were hypothesised to be in the factor that we called "provider-based adherence" (Table 1).

Extracted factors from the CFA were tested for their internal consistency reliability by factor score determinacy (FSD) [16], which is the certainty with which factor axes are fixed in the variable space and represents the squared multiple correlations of factor scores predicted from scores on observed variables. A factor is considered stable and with adequate internal consistency when the FSD has a value $\geq 0.70[16]$

The floor and ceiling effect of the EHFScBS-9 overall and of its individual factors were evaluated determining the percentage of the patients who obtained the minimum and the maximum possible score, respectively. An instrument is considered acceptable if both percentages are $<15 \%$ [19].

The responsiveness to changes (that is a measure of an instrument's precision) of the EHFScBS-9 overall and of its individual factors was computed with the standard error of measurement (SEM) and the smallest real differences (SRD). The SEM is an indication of the dispersion of the measurement errors when trying to estimate individual true scores from their observed test scores [20]. This was computed with the following formula: SD X $\sqrt{ }(1-$ reliability coefficient, whereby the reliability coefficient considered for this computation was the FSD. An instrument with a SEM $<\mathrm{SD} / 2$ is considered precise to measure a variable [21]. The SRD is the smallest variation in an instrument score that can be interpreted as a real difference [22] and was calculated with the following formula: $1.96 \mathrm{X} \sqrt{ } 2 \mathrm{X}$ SEM. The smaller the SEM and the SRD, the more precise is the scale.

The SPSS 19.0 and Mplus 6.0 were the statistical software used to analyse the data.

\section{Results}

\subsection{Sociodemographic and clinical characteristics of the sample}


Participants had a mean age of 72 years $(\mathrm{SD}=11)$ and were mostly male $(58 \%)$. Education was quite low, as only $20 \%$ of the sample had completed high school or university studies. Most patients were married (57\%) and unemployed (82\%). NYHA functional classes were all represented in the sample. The mean ejection fraction was $45 \%$ and the median duration of illness was 38 months (Table 2).

\subsection{Item analysis of the EHFSCBS-9}

Item analysis (Table 3) showed that the most frequently performed self-care behaviours (score 1) were taking the medicines regularly, eating a low-salt diet, and limiting fluid intake, whereas the less frequent self-care behaviours (score 5) were contacting provider in case of gaining weight, exercising regularly, and contacting provider if dyspnoea occurred. The mean of the "classic" total score of the EHFScBS-9 was 23.9. We also computed the reversed and standardised $0-100$ score with a higher score meaning better self-care, which was 58.3. The two above scores had a perfect negative correlation $(-1.0, \mathrm{p}<0.000)$ meaning that the two scores are identical in the measurement properties.

\subsection{Construct validity of the EHFScBS-9}

The hypothesised measurement model including three factors was supported in the CFA with the following fit indices: $\chi^{2}(23)=168.06$, p 0.000, RMSEA $=0.073(90 \%$ C.I. $0.06-0.08)$; CFI $=$ 0.96; NNFI $=0.95 ;$ SRMR $=0.04$ (Figure 1$)$.

\subsection{Reliability of the EHFScBS-9}


Internal consistency reliability computed by factor score determinacy showed that the three factors resulting from the CFA exhibited good coefficients: 0.95 for the consulting behaviours factor, 0.82 for the autonomous-based adherence, and 0.77 for the provider-based adherence.

\subsection{Floor, ceiling effect and responsiveness to change of the EHFScBS-9}

Table 4 shows that the floor and ceiling effect of the EHFScBS-9 overall and its three factors were below $15 \%$, except for the provider-based adherence that showed a ceiling effect of $33.5 \%$. The highest SEM and SRD were observed for the autonomous-based adherence and the provider-based adherence, whereas the lower were observed for the EHFScBS-9 overall and the consulting behaviours factor.

\section{Discussion and Conclusion}

\subsection{Discussion}

This study is a step forward in the measurement of patient-reported outcomes of self-care. Firstly, in addition to confirming the existence of the consulting behaviours factor also in this study, we identified two other factors that we named autonomous-based adherence and provider-based adherence. This novel factorial structure gives new insights into the EHFScBS-9, resulting in the possibility to evaluate in patients a total self-care as well as three separate sub-dimensions of selfcare which have valid and reliable properties. It was interesting to note that similar to the factorial structure of the SCHFI v.6.2, in the EHFScBS-9 we identified an "autonomous" adherence consisting of healthy behaviours endorsed by patients (e.g. weighing every day or exercising) and an adherence based on the provider's "prescription" (e.g., taking medicines). These findings reinforce prior theoretical orientation which states that self-care is a broader dimension and not 
merely the adherence to treatment [23-25]. Interestingly, the SCHFI v.6.2 and the EHFScBS-9, that were seen in prior studies as measuring different constructs [26], resulted in a very similar factorial structure in this study. Compared to prior studies where the factorial structure of the EHFScBS-9 has been tested, in ours the fit indices were even better.

The factor score determinacy resulted in adequate coefficients which demonstrated three reliable factors within the EHFScBS-9. Prior studies had found that the adherence to regimen factor had poor reliability, thus it was advised not to be used separately [8-10]. Instead, we found two factors measuring adherence (the autonomous-based adherence and the provider-based adherence) which had good reliability, and can be used to measure these two dimensions.

Another novel finding that we identified was through measurement of the precision of the EHFScBS-9. We found that only the provider-based adherence exhibited a ceiling effect above the range of $15 \%$. This result was expected because it has been shown that the adherence to pharmacological treatment is the most frequent behaviour in people with HF [27]. Moreover, the SEM was very small for the scale and its factors since it was below half of the SD. The SRD is another new insight into the EHFScBS-9 because it gives the amount of points the scale should increase or decrease to be sure that a real difference in self-care has occurred in patients.

This is the first time that a reversed standardised score of the EHFScBS-9 is presented, with a higher score on a scale of 0 - 100 meaning better self-care. We think this modification would allow for a better understanding of the EHFScBS-9 score and easier comparison with the SCHFI v.6.2, which uses the same standardised score. In fact, in a recent study carried out in 15 countries worldwide where both instruments were used [27], the investigators could only select specific items from the two instruments to compare and could not attempt a comparison of the total score. Therefore, comparisons of "global" self-care were limited. With this new scoring procedure the two instruments have the same range $(0-100)$ and the same meaning in score (higher score $=$ better 
self-care), which we think may be useful for international and cross-cultural comparisons. In the Appendix we give the SPSS syntax for the computation of the 0 - 100 score of the EHFScBS-9.

This study has several limitations. Even though patients were recruited in 28 provinces across Italy a convenience sample was used. Since these provinces were mainly located in central Italy, individuals living in Northern and Southern Italy were less represented and therefore, differences in healthcare access or clinical care in those areas need to be further studied. Another limitation is that the sample was heterogeneous in term of sociodemographic (e.g. age or gender) and clinical characteristics (e.g. NYHA functional class or comorbidity), factors known to affect self-care. However sample heterogeneity may be considered a strength in this study and may increase generalizability of psychometric properties of the EHFScBS-9 within the Italian population. In addition, this study used a cross-sectional design, so we could only test the internal consistency reliability of the EHFScBS-9. Future research should use a longitudinal study design to evaluate the test-retest reliability in order to give an estimate of the stability of the measure.

The factorial structure of the EHFScBS-9 identified in this study should be generalised with caution in other populations. For instance, while the consulting behaviours factor seems stable across populations as found in prior studies, the adherence to regimen varies [8-10], so we recommend users to test the factorial structure of the EHFScBS-9 before its use in clinical practice and research in specific populations.

\subsection{Conclusion}

In conclusion, we showed in this study that the EHFScBS-9 has supportive psychometric properties of validity, reliability, and precision, and its use is recommended to measure self-care behaviours in clinical practice and research.

\subsection{Practice implication}


The number of patients suffering from HF is increasing worldwide with an impact on health care costs. Education to improve self-care in HF has been found to be effective to reduce its burden on individuals, families and society $[28,29]$. This study reinforces prior validity and reliability testing of the EHFScBS-9 and expand on practice implications for its use. According to the results of this study researchers and clinicians can measure patient's self-care by computing a total score, but also by computing scores for each sub-dimension of self-care: consulting behaviour, autonomybased adherence, and provider-based adherence. Use of these subscale scores would allow more detailed assessment of self-care and more tailored interventions to improve self-care, that, for example, might focus on autonomous-based adherence over provider-based adherence. Another practice implication of this study is computation of the SRD for the EHFScBS-9: we should see at least an increase of 5.75 points in the total standardised $0-100$ score to state that a modification in a patient's self-care has occurred. Finally, the standardized $0-100$ score proposed in this study provides a better understanding of the EHFScBS-9 score. 


\section{Funding}

This work was funded by the Center of Excellence for Nursing Scholarship, Rome, Italy.

\section{Conflict of Interest:}

None declared.

We confirm all patient identifiers have been removed or disguised so the patients described are not identifiable and cannot be identified through the details of the story. 


\section{References}

[1] McMurray JJ, Adamopoulos S, Anker SD, Auricchio A, Bohm M, Dickstein K, et al. ESC guidelines for the diagnosis and treatment of acute and chronic heart failure 2012: The Task Force for the Diagnosis and Treatment of Acute and Chronic Heart Failure 2012 of the European Society of Cardiology. Developed in collaboration with the Heart Failure Association (HFA) of the ESC. Eur J Heart Fail 2012;14:803-69.

[2] Buck HG, Lee CS, Moser DK, Albert NM, Lennie T, Bentley B, et al. Relationship Between Self-care and Health-Related Quality of Life in Older Adults With Moderate to Advanced Heart Failure. J Cardiovasc Nurs 2012;27:8-15.

[3] Wu JR, Corley DJ, Lennie TA, Moser DK. Effect of a medication-taking behavior feedback theory-based intervention on outcomes in patients with heart failure. J Card Fail 2012;18:1-9. [4] Jaarsma T, Stromberg A, Martensson J, Dracup K. Development and testing of the European Heart Failure Self-Care Behaviour Scale. Eur J Heart Fail 2003;5:363-70.

[5] Riegel B, Lee CS, Dickson VV, Carlson B. An update on the self-care of heart failure index. J Cardiovasc Nurs 2009;24:485-97.

[6] Cameron J, Worrall-Carter L, Driscoll A, Stewart S. Measuring self-care in chronic heart failure: a review of the psychometric properties of clinical instruments. J Cardiovasc Nurs 2009;24:E10-22.

[7] Vellone E, Riegel B, Cocchieri A, Barbaranelli C, D'Agostino F, Glaser D, et al. Validity and Reliability of the Caregiver Contribution to Self-care of Heart Failure Index. J Cardiovasc Nurs 2013;28:245-55.

[8] Jaarsma T, Arestedt KF, Martensson J, Dracup K, Stromberg A. The European Heart Failure Self-care Behaviour scale revised into a nine-item scale (EHFScB-9): a reliable and valid international instrument. Eur J Heart Fail 2009;11:99-105. 
[9] Koberich S, Glattacker M, Jaarsma T, Lohrmann C, Dassen T. Validity and reliability of the German version of the 9-item European Heart Failure Self-care Behaviour Scale. Eur J Cardiovasc Nurs 2013;12:150-8.

[10] Lee CS, Lyons KS, Gelow JM, Mudd JO, Hiatt SO, Nguyen T, et al. Validity and reliability of the European Heart Failure Self-care Behavior Scale among adults from the United States with symptomatic heart failure. Eur J Cardiovasc Nurs 2013;12:214-8.

[11] Cooper H. APA Handbook of research methods in psychology. Washington, DC: American Psychological Association; 2012.

[12] Vellone E, Riegel B, Cocchieri A, Barbaranelli C, D'Agostino F, Antonetti G, et al. Psychometric properties of the self-care of heart failure index version 6.2. Res Nurs Health 2013; In press.

[13] Kottner J, Streiner D. Internal consistency and Cronbach's: A comment on Beeckman et al. (2010). Int J Nurs Stud 2010;47:926-8.

[14] Raykov T. Scale reliability, Cronbach's coefficient alpha, and violations of essential tauequivalence for fixed congeneric components. Multivariate Behavioral Research 1997;32:329-54. [15] Raykov T. Scale Construction and Development Using Structural Equation Modeling. New York: The Guilford Press; 2013.

[16] Tabachnick BG, Fidell LS. Using Multivariate Statistics. 6th ed. Boston Allyn \& Bacon; 2013. [17] Brown TA. Confirmatory factor analysis for applied research. New York: The Guilford Press; 2006.

[18] Hu L, Bentler PM. Cutoff criteria for fit indexes in covariance structure analysis: Conventional criteria versus new alternatives. Struct Equ Modeling 1999;6:1-55.

[19] McHorney CA, Tarlov AR. Individual-patient monitoring in clinical practice: are available health status surveys adequate? Qual Life Res 1995;4:293-307.

[20] Brown JD. Standard er ror vs. Standard er rrorr off measurrementt. Shiken: JALT Testing \& Evaluation SIG Newsletter 1999;3:20-5. 
[21] Wyrwich KW, Nienaber NA, Tierney WM, Wolinsky FD. Linking clinical relevance and statistical significance in evaluating intra-individual changes in health-related quality of life. Medical Care 1999;37:469-78.

[22] Beckerman H, Roebroeck ME, Lankhorst GJ, Becher JG, Bezemer PD, Verbeek AL. Smallest real difference, a link between reproducibility and responsiveness. Qual Life Res 2001;10:571-8. [23] Riegel B, Dickson VV. A situation-specific theory of heart failure self-care. J Cardiovasc Nurs 2008;23:190-6.

[24] Riegel B, Jaarsma T, Stromberg A. A middle-range theory of self-care of chronic illness. ANS Adv Nurs Sci 2012;35:194-204.

[25] Vellone E, Riegel B, D'Agostino F, Fida R, Rocco G, Cocchieri A, et al. Structural Equation Model Testing the Situation-specific Theory of Heart Failure Self-Care. Adv Nurs doi: 10.1111/jan.12126. Published online epub ahead of print 2013 Mar 21.

[26] Shuldham C, Theaker C, Jaarsma T, Cowie MR. Evaluation of the European Heart Failure Self-care Behaviour Scale in a United Kingdom population. J Adv Nurs 2007;60:87-95.

[27] Jaarsma T, Strömberg A, Ben Gal T, Cameron J, Driscoll A, Duengen H, et al. Comparison of self-care behaviours of heart failure patients in 15 countries worldwide. Patient Educ Couns 2013;92:114-20.

[28] Stamp KD, Machado MA, Allen NA. Transitional Care Programs Improve Outcomes for Heart Failure Patients: An Integrative Review. J Cardiovasc Nurs 2013.

[29] Corotto PS, McCarey MM, Adams S, Khazanie P, Whellan DJ. Heart failure patient adherence: epidemiology, cause, and treatment. Heart Fail Clin 2013;9:49-58. 


\section{Appendix}

SPSS syntax to compute the $0-100$ standardised and reversed score of the EHFScBS-9, where a higher score means better self-care.

Syntax to reverse each item:

RECODE

item_n $(1=5)(2=4)(3=3)(4=2)(5=1)$ INTO R_item_n.

EXECUTE.

Syntax to compute the $0-100$ standardised score (after item reverse):

COMPUTE

EHFScBS_9=(SUM(R_item_1,R_item_2,R_item_3,R_item_4,R_item_5,R_item_6,R_item_7,R_ite m_8,R_item_9)-9)*2.7777. EXECUTE. 
Table 1. The hypothesised factorial structure of the EHFScBS-9 used to perform confirmatory factor analysis

$\begin{array}{ll}\text { Items } & \text { Factors }\end{array}$

1. I weigh myself every day

Autonomous-based

5. I limit the amount of fluids

adherence

9. I exercise regularly

2. If SOB increases I contact my doctor or nurse

Consulting behaviour

3. If legs/feet are more swollen, I contact my doctor or nurse

4. If I gain weight more than $2 \mathrm{~kg}$ in 7 days I contact my doctor or

nurse

6. If I experience fatigue I contact my doctor or nurse

7. I eat a low-salt diet

Provider-based adherence

8. I take my medication as prescribed

SOB, shortness of breath 
Table 2.Sociodemographic and Clinical Characteristics of the Sample $(\mathrm{N}=1192)$

\begin{tabular}{|c|c|}
\hline Variables & $\mathrm{N}(\%)$ \\
\hline Age (mean, SD) & $72.36(11.2)$ \\
\hline \multicolumn{2}{|l|}{ Gender } \\
\hline Male & $694(58.2)$ \\
\hline Female & $498(41.8)$ \\
\hline \multicolumn{2}{|l|}{ Education } \\
\hline Elementary & $546(45.8)$ \\
\hline Middle School & $294(24.7)$ \\
\hline Professional School & $110(9.3)$ \\
\hline High School & $171(14.3)$ \\
\hline University Degree & $71(6.0)$ \\
\hline \multicolumn{2}{|l|}{ Marital Status } \\
\hline Married & $677(56.8)$ \\
\hline Single & $80(6.7)$ \\
\hline Widowed & $358(30.0)$ \\
\hline Divorced & $77(6.5)$ \\
\hline \multicolumn{2}{|l|}{ Profession } \\
\hline Employed & $214(18.0)$ \\
\hline Unemployed or retired & $978(82.0)$ \\
\hline \multicolumn{2}{|l|}{ NYHA Class } \\
\hline I & $197(16.6)$ \\
\hline II & $508(42.6)$ \\
\hline III & $394(33.0)$ \\
\hline IV & $93(7.8)$ \\
\hline Ejection Fraction (Mean, SD) & $44.66(10.8)$ \\
\hline $\begin{array}{l}\text { Months since diagnosis (Median, } \\
\text { Interquartile range) }\end{array}$ & $38(24-68)$ \\
\hline
\end{tabular}

NYHA, New York Heart Association; SD, standard deviation 
Table 3. Item analysis of the EHFScBS-9 $(n=1192)$

\begin{tabular}{|c|c|c|c|c|c|c|}
\hline \multirow[t]{2}{*}{ Item } & \multirow{2}{*}{$\begin{array}{l}\text { Median } \\
\text { (interquartile } \\
\text { range) } \\
\end{array}$} & \multicolumn{5}{|c|}{ Percentages of responses per each Likert point } \\
\hline & & 1 & 2 & 3 & 4 & 5 \\
\hline 1. I weigh myself every day & $3(2-4)$ & 13.7 & 21.5 & 29.4 & 19.5 & 16.0 \\
\hline 2. If SOB increases I contact my doctor or nurse & $3(2-4)$ & 22.3 & 24.2 & 21.4 & 12.5 & 19.5 \\
\hline 4. If I gain weight more than $2 \mathrm{~kg}$ in 7 days I contact my doctor or nurse & $3(2-5)$ & 14.9 & 21.1 & 20.5 & 16.6 & 26.9 \\
\hline 5. I limit the amount of fluids & $3(2-4)$ & 24.5 & 24.3 & 23.6 & 14.0 & 13.6 \\
\hline 6. If I experience fatigue I contact my doctor or nurse & $3(2-4)$ & 23.2 & 22.6 & 21.8 & 13.6 & 18.9 \\
\hline 9. I exercise regularly & $3(2-4)$ & 19.2 & 17.5 & 23.3 & 19.5 & 20.6 \\
\hline Total "Classic" score (Mean, SD) & $23.9(6.9)$ & & & & & \\
\hline Total "Reversed and Standardised" score (Mean, SD) & $58.3(19.2)$ & & & & & \\
\hline
\end{tabular}

Note. The total "Classic" score reports the mean (and SD) of the usual score computed for the EHFScBS-9 where higher score means worse selfcare (possible range $9-45$ ). The total "Reversed and Standardised" score reports the mean (and SD) computed for the EHFScBS-9 on a $0-100$ scale where higher score means better self-care. SOB, shortness of breath 
Figure 1. Confirmatory factor analysis of the EHFScBS-9 $(n=1192)$

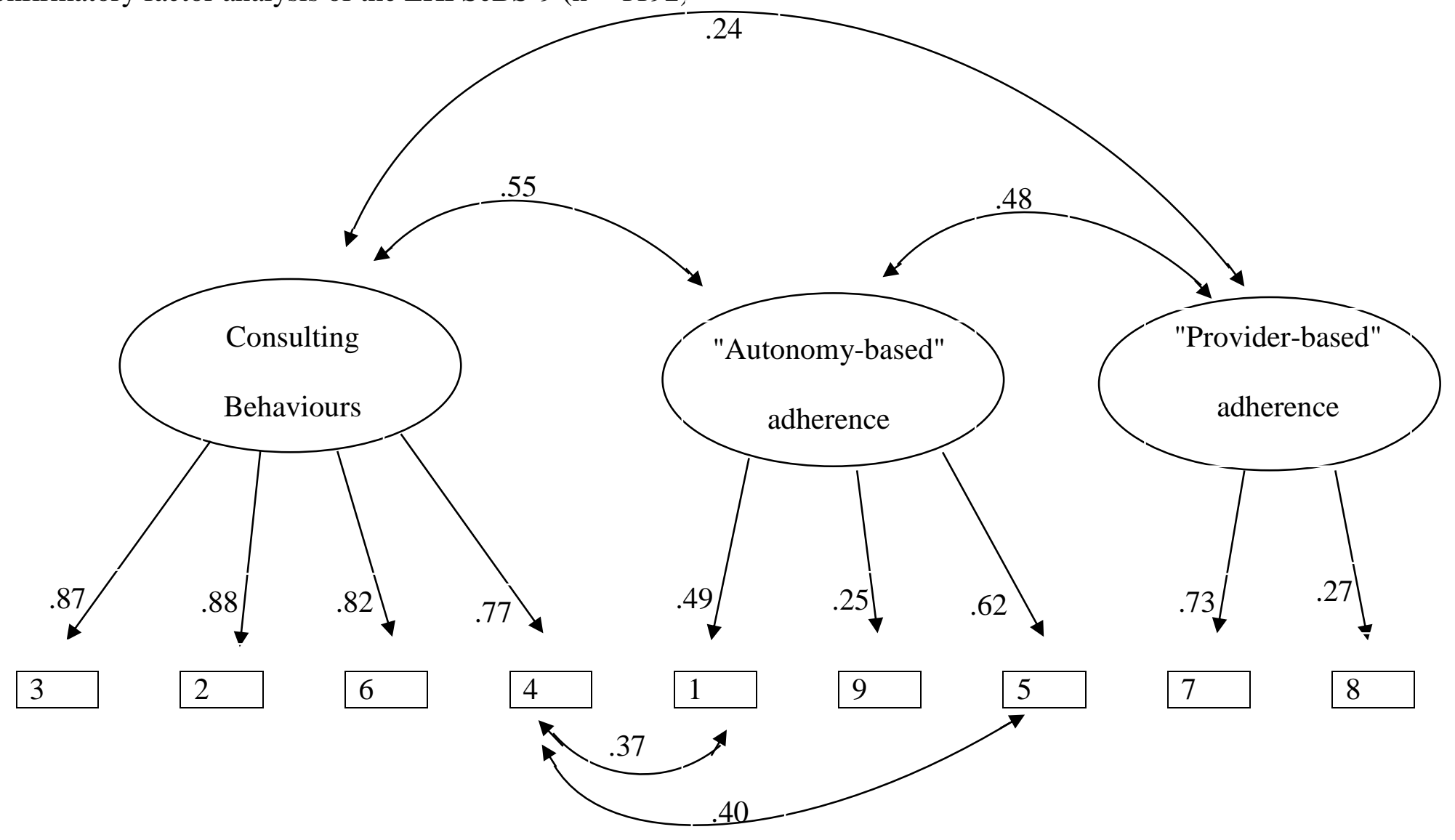


Table 4. Floor, ceiling effect and responsiveness to change of the EHFScBS-9

\begin{tabular}{lccccc}
\hline Scale/Factor & M (SD) & Floor effect & Ceiling effect & SEM & SRD \\
& & $(\%)$ & $(\%)$ & \\
\hline EHFScBS overall & $58.3(19.2)$ & 0 & 1.2 & 4.3 & 5.7 \\
Autonomous-based & $51.93(23)$. & 2.1 & 2.7 & 10 & 8.8 \\
adherence & & & & \\
Provider-based & $80.05(19.4)$ & 0.2 & 33.5 & 9.3 & \\
adherence & & & & & \\
Consulting behaviours & $49.98(16.8)$ & 0.2 & 0.1 & 3.8 & 5.4
\end{tabular}

Note. All scale and factors' scores are standardised to $0-100$ points with higher scores meaning better self-care. The floor and the ceiling effect are the percentage of the patients who obtained the minimum and the maximum possible score respectively. SEM = Standard error of measurement; $\mathrm{SRD}=$ smallest real difference. 